\title{
A 17 GHz HIGH GRADIENT LINAC HAVING STAINLESS STEEL SURFACES IN THE HIGH INTENSITY MAGNETIC AND ELECTRIC FIELD REGIONS OF THE STRUCTURE*
}

\author{
J. Haimson and B. Mecklenburg \\ Haimson Research Corporation, Santa Clara, CA 95054-3104, U.S.A.
}

\section{Abstract}

To avoid surface erosion damage and to assist in understanding RF breakdown limitations imposed on high gradient linac operation, a gradient hardened structure is being fabricated having high temperature brazed and machined stainless steel surfaces located in the high Efield region of the beam apertures and in the high $\mathrm{H}$-field regions of the racetrack shaped coupling cavities. The microwave design parameters and physical dimensions of this $17 \mathrm{GHz}, 2 \pi / 3$ mode, 22-cavity structure were established specifically to allow comparison of its high gradient performance to that of a similar all-copper structure tested under identical conditions, using an existing $4 \mathrm{X}$ power amplifying, $\mathrm{RF}$ recirculating dual ring system. Use of the $6 \mathrm{X}$ thicker skin depth material, the resulting de-Q-ing effects and the minimal reduction of beam energy $(2 \%)$ associated with the strategically located lossy surfaces are discussed; fabrication techniques are described; and design parameters of the gradient hardened linac and the $17 \mathrm{GHz}$ power amplifying system are presented.

\section{INTRODUCTION}

The results of high power experiments with full length linear accelerator structures $[1,2,3]$ using RF pulse widths in the range of 100 to 400 ns have indicated that the maximum accelerating gradient is essentially independent of the operating frequency. Moreover, an extensive $11.4 \mathrm{GHz}$ test program at SLAC using copper structures has established the accelerating gradient upper limit for acceptable long term operation to be approximately $65 \mathrm{MV} / \mathrm{m}$. Attempts to operate disc loaded TW structures at higher gradients, to satisfy the $>100 \mathrm{MV} / \mathrm{m}$ requirement for future linear colliders, have resulted in RF breakdown at the disc irises and coupling cavity apertures; and in some instances, permanent phase changes have occurred due to erosion of the copper surfaces.

To assist in understanding the limitations imposed on high gradient operation, and to minimize surface damage, a gradient hardened $17 \mathrm{GHz} \mathrm{TW}$ linac structure is being fabricated using high temperature brazed, non-magnetic stainless steel inserts in the high $\mathrm{H}$-field regions of the dual feed, racetrack shaped input coupler cavity at the lips of the side wall coupling apertures, and in the high E-field region of the disc irises, as indicated in Figure 1. This work is based on a previously described technique [1] that made use of the superior high temperature strength

*Work performed under the auspices of the U.S. Department of Energy SBIR Grant No. DE-FG02-05ER84362.

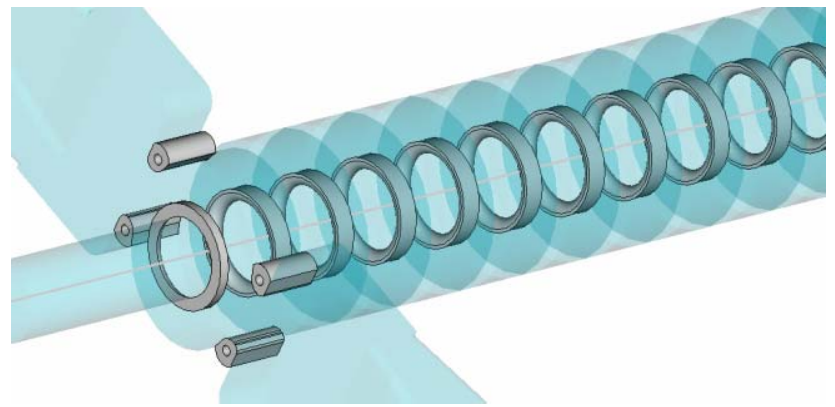

Figure 1: Location of brazed stainless steel inserts.

properties of stainless steel (refer Table 1) to solve an electric field surface erosion problem encountered after long service with a prototype high power TW output structure in a $17 \mathrm{GHz}$ relativistic klystron.

Table 1: Parameter Comparison of Materials

\begin{tabular}{|l|c|c|}
\hline \multicolumn{1}{|c|}{ Parameter } & $\begin{array}{c}\text { OFHC } \\
\text { Copper }\end{array}$ & $\begin{array}{c}\text { Type 304 } \\
\text { Stainless Steel }\end{array}$ \\
\hline Tensile Strength (psi) & $28000^{*}$ & 79000 \\
Yield Strength (psi) & 2000 & 35000 \\
Modulus of Elasticity (psi) & $16 \times 10^{6}$ & $29 \times 10^{6}$ \\
Maximum Elongation (\%) & 60 & 54 \\
Melting Temp. $\left({ }^{\circ} \mathrm{C}\right)$ & 1083 & $1454-1499$ \\
\hline
\end{tabular}

* At room temperature

\section{X POWER AMPLIFIER IMPLICATIONS}

The microwave parameters and physical dimensions of the gradient hardened linac test structure were designed to match the feedback loop insertion loss and the mechanical interface requirements of the high peak power dual ring RF recirculating system shown schematically in Figure 2. In this system, two $6 \mathrm{~dB}$ hybrids are attached directly to the linac test structure to form two parallel feedback loops so that, on the initial pass, $25 \%$ of the source RF power

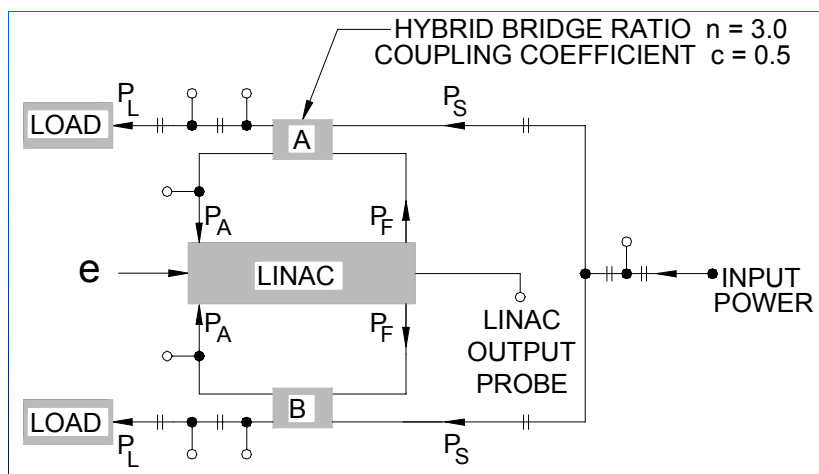

Figure 2: 4X Power amplifier dual recirculating rings with an embedded $17 \mathrm{GHz}$ linac test structure. 
enters the linac, and $75 \%$ is transmitted to the loads. For a loop loss of $1.25 \mathrm{~dB}$ (including beam loading), $75 \%$ of the linac input power will be returned to the bridge; and with a correctly phased feedback loop, $75 \%$ of this returned power will be added to the linac input power, and $25 \%$ (in counter phase) will cause a load power reduction. After 20 successive loop recirculations, the load arm power will be reduced to zero, and the linac input power will build up to a level 4 times greater than the source power, as indicated in Figure 3. After full buildup is attained, a constant power level will be maintained until the source pulse is terminated. Thus, a loop transit time of $11 \mathrm{~ns}$ is required to achieve an RF flattop of $150 \mathrm{~ns}$ with a source pulse width of $370 \mathrm{~ns}$.

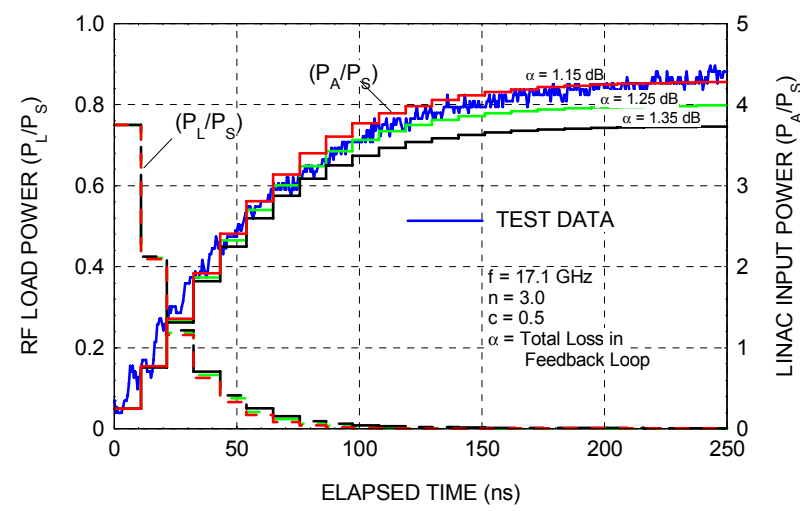

Figure 3: 4X Power buildup and load power decay during successive recirculations.

To ensure that the loop loss and transit time parameters of the power amplifier would be conserved when operating with the gradient hardened linac structure, the de-Q-ing effects of using different configuration stainless steel inserts were studied; and means of compensating for these effects were investigated.

\section{STAINLESS STEEL INSERTS}

The gradient hardened structure was designed to duplicate the phase orbit characteristics of the 22-cell, allcopper linac structure presently integrated into the $4 \mathrm{X}$ power amplifier. This structure, shown in Figure 4, incorporates cavities with phase velocities slightly larger than c to provide correct asymptotic bunch location for high gradient operation with a $550 \mathrm{kV}$ injector.

Although 304 stainless steel has a surface resistivity $\approx 6$ times greater than annealed high purity copper, it was possible to avoid undesirable degradation of the cavity $\mathrm{Q}$ by limiting the brazed inserts to only that small fraction of the cavity surface exposed to high surface fields. The iris contour of the stainless steel insert in each $1.45 \mathrm{~mm}$ thick copper disc was formed by using $0.68 \mathrm{~mm}$ radii smoothly blended from the sides of the disc to a $0.09 \mathrm{~mm}$ flat in the bore, with extension along the disc sides to a region where the surface E-field is reduced to $65-70 \%$ of the maximum value. Simulation results indicated that, for the range of cavity parameters considered $(\mathrm{a} / \lambda=0.14$ to 0.18 , and phase velocities from $\mathrm{c}$ to $1.015 \mathrm{c}$ ), the use of $304 \mathrm{~L}$ stainless steel brazed inserts in the disc irises would result in a $\mathrm{Q}$

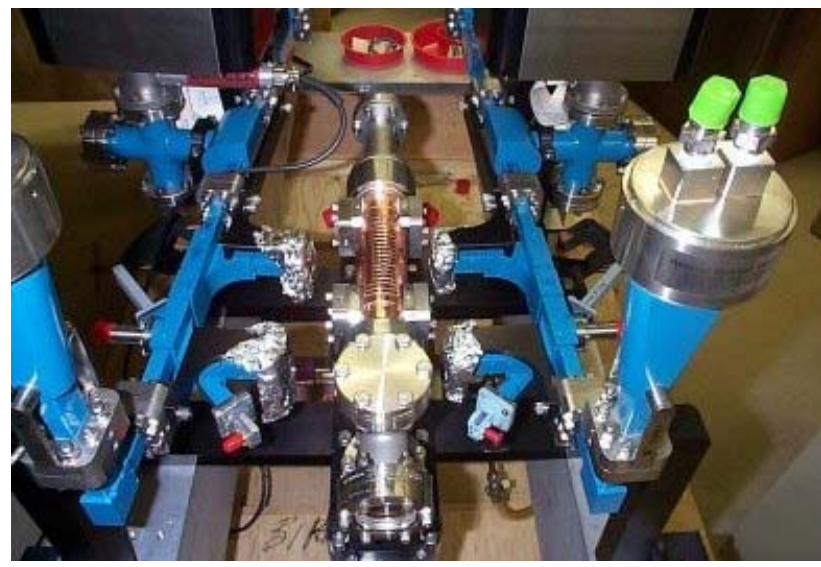

Figure 4: $17 \mathrm{GHz}$ linac all-copper structure in the $4 \mathrm{X}$ peak power amplifier system.

reduction of $16 \%$. It can be noted that, even with a linac attenuation parameter as high as $\tau=0.3 \mathrm{~Np}$ (more than twice the value required for this application), a $16 \%$ increase in the surface loss of a near-uniform impedance structure will result in only a $2 \%$ reduction of beam energy because the product of the unit length increased attenuation and reduced shunt impedance remains essentially constant, and the beam energy is proportional to $\left(1-\mathrm{e}^{-\tau}\right) / \tau$.

To compensate for the de-Q-ing effect of the stainless steel so that the required loop loss is maintained, the disc iris diameter of the gradient hardened structure was made $5.4 \%$ larger than the all-copper structure, and the system design parameters were finalized, as listed in Table 2.

The dual feed, racetrack-shaped input coupler configuration simulated in Figure 5, shows the location of the stainless steel inserts (and associated copper heat sink holes) that form the lips of the coupling apertures. The magnetic field values shown at the surface of the cavity wall and coupling aperture are normalized to the peak of the modified Bessel function (100), and indicate that, with a compact single cell coupler assembly, the use of thick asymmetrically radiused lips can limit the magnetic field enhancement to a moderate value $(2 \cdot 2: 1)$.

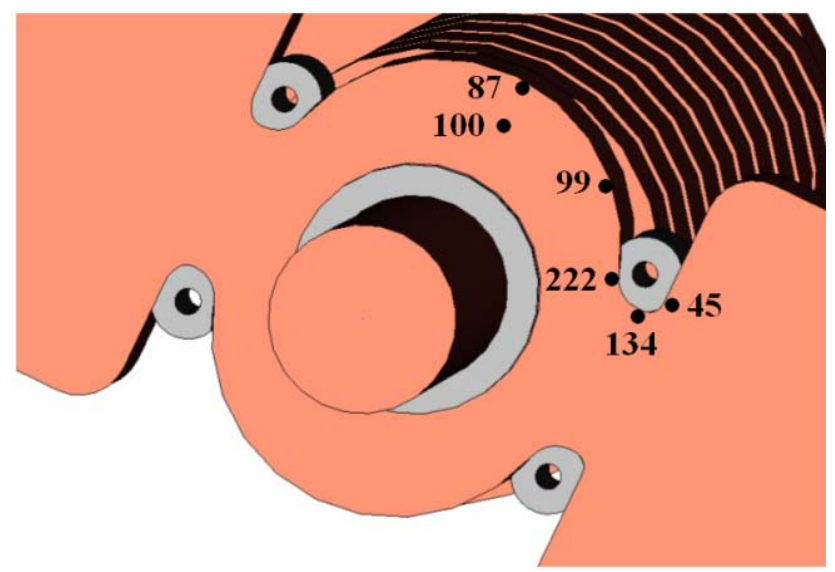

Figure 5: Racetrack cavity configuration showing the normalized values of the magnetic field, the copper heat sink holes, and the stainless steel brazed inserts forming the asymmetrically radiused lips of the coupling apertures. 
Table 2: Design Parameters of the Gradient Hardened $17 \mathrm{GHz}$ Linac Structure and the Power Amplifier

\begin{tabular}{|c|c|}
\hline Frequency & $17136 \mathrm{MHz}$ \\
\hline Operating Mode & $2 \pi / 3$ \\
\hline \multicolumn{2}{|l|}{ Number of Cavities (including } \\
\hline Racetrack Couplers) & 22 \\
\hline Cavity Phase Velocities & $\begin{array}{r}4 \text { at c, } 2 \text { at } 1.005 \mathrm{c}, 2 \text { at } \\
1.010 \mathrm{c} \text {, and } 14 \text { at } 1.015 \mathrm{c}\end{array}$ \\
\hline Disc Thickness & $1.45 \mathrm{~mm}$ \\
\hline Stainless Steel Iris Diameter & $6.00 \mathrm{~mm}$ \\
\hline Number of Stainless Steel Irises & 23 \\
\hline Stainless Steel Skin Depth & $3.1 \mu \mathrm{m}$ \\
\hline Copper Skin Depth & $0.51 \mu \mathrm{m}$ \\
\hline $\begin{array}{l}\text { Structure Attenuation Parameter } \\
\text { (including stainless steel irises) }\end{array}$ & $0.124 \mathrm{~Np}(+$ lips $)$ \\
\hline \multicolumn{2}{|l|}{ Linac Structure Harmonic Mean } \\
\hline Group Velocity & $0.044 \mathrm{c}$ \\
\hline Linac Structure Filling Time & $9.7 \mathrm{~ns}$ \\
\hline \multicolumn{2}{|l|}{ Output Phase/Frequency } \\
\hline Sensitivity of Linac Structure & $3.5 \mathrm{deg} / \mathrm{MHz}$ \\
\hline \multicolumn{2}{|l|}{ Output Phase/Temperature } \\
\hline Sensitivity of Linac Structure & $1.0 \mathrm{deg} /{ }^{\circ} \mathrm{C}$ \\
\hline Feedback Loop Transit Time & $11.2 \mathrm{~ns}$ \\
\hline Feedback Loop Total Loss & $1.25 \mathrm{~dB}$ \\
\hline Feedback Loop Total Phase & $8280 \mathrm{deg}$ \\
\hline Feedback Loop Phase Dispersion & $4.1 \mathrm{deg} / \mathrm{MHz}$ \\
\hline \multicolumn{2}{|l|}{ Time to Attain $99.5 \%$ Steady } \\
\hline State RF Power Buildup & $210 \mathrm{~ns}$ \\
\hline Input Power to Dual Ring & $20 \mathrm{MW}$ \\
\hline Linac Input Power & $80 \mathrm{MW}$ \\
\hline Average Accelerating Gradient & $101 \mathrm{MV} / \mathrm{m}$ \\
\hline Maximum Surface Gradient & $236 \mathrm{MV} / \mathrm{m}$ \\
\hline
\end{tabular}

\section{FABRICATION DETAILS}

Brazing and machining investigations to ensure voidfree bonding of the metal inserts resulted in the use of prefabricated mixed metal billets brazed at a higher temperature than the subsequent gold-copper alloy brazing of the final machined components. Figure 6 shows typical billet assemblies for body cavities and RF cut-off noses, and the embedded stainless steel buttons and cylinders that formed the final machined disc iris inserts. Also shown are racetrack coupler billets with

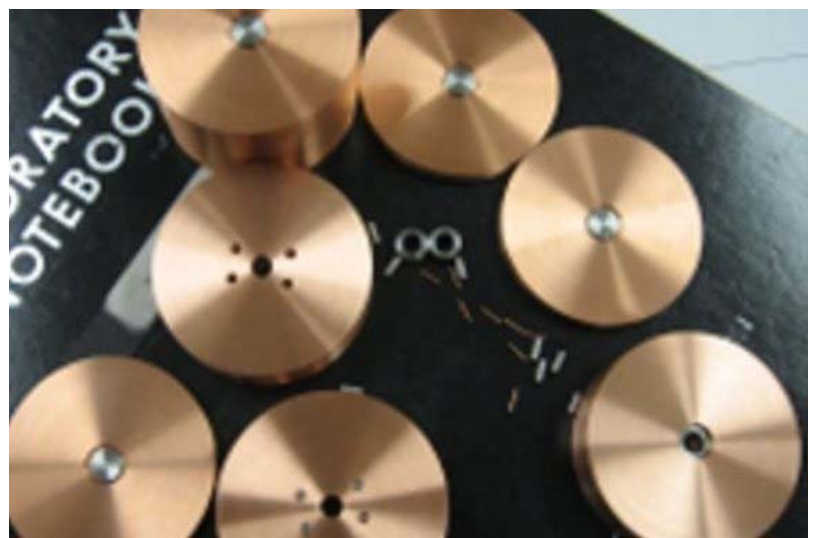

Figure 6: Mixed metal billets being prepared for nickel alloy brazing prior to preliminary and final machining.
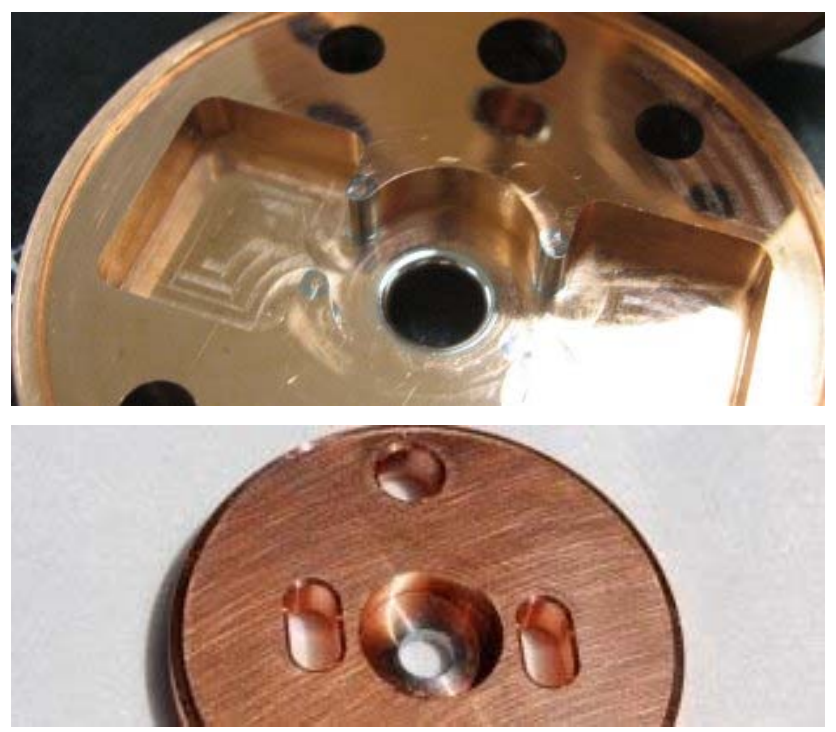

Figure 7: High temperature brazed stainless steel inserts and copper heat sinks shown in the racetrack input coupler, and a typical iris insert cavity, prior to final machining.

accurately pre-located holes for positioning the hollow stainless steel posts and copper heat sink pins that formed the asymmetrically radiused coupler lips in a subsequent milling operation, as shown in the upper photograph of Figure 7.

Accurately reproducible values of passband and resonant frequency, measured after repeated braze cycles using stainless steel iris cavity test assemblies, have confirmed the geometric stability of this configuration. Similar tests using high temperature brazed molybdenum iris inserts were also satisfactorily performed; these resulted in a slight increase in resonant frequency.

\section{CONCLUSIONS}

Despite the increase in surface resistivity of stainless steel compared to copper, because of the superior high temperature strength characteristics and the substantially greater skin depth, there are empirical and theoretical arguments suggesting that the use of stainless steel should enable high gradient operation at surface temperatures in excess of values associated with surface damage in copper cavities. High power $17 \mathrm{GHz}$ linac tests are planned to evaluate the validity of these arguments and to determine if they influence the threshold value for reliable high gradient operation.

\section{REFERENCES}

[1] Structure Breakdown Workshop, SLAC, Stanford, August 2000, http://www-project.slac.stanford.edu/lc/ wkshp/RFBreakdwn/struct_breakdown_wkshp.htm.

[2] Workshop on High Gradient RF Cavities, Argonne National Lab., Oct. 1993, http://www.hep.anl.gov/rf/.

[3] US Workshop on High Gradient Research for Multi TeV Linear Colliders, SLAC, Stanford, July 2005, http://www.slac.stanford.edu/grp/ara/HGWorkshop/H GWorkshop.htm. 